\title{
Moda desconstrutivista à la Jacques Derrida: um conceito estético ou \\ "defeito" de construção?
}

\section{Deconstructive fashion from Jacques Derrida: an aesthetic concept or "defect" of construction?}

\author{
Cristiano Max Pereira Pinheiro \\ Doutor em Comunicação Social pela Pontifícia Universidade Católica do Rio Grande do Sul (PUCRS). Professor da \\ Universidade Feevale - maxrs@feevale.br - https://orcid.org/0000-0002-2038-8191 \\ Milena Cherutti \\ Mestranda em Indústria Criativa pela Universidade Feevale - mcherutti@hotmail.com - https://orcid.org/0000-0001- \\ 7495-3777
}

\begin{abstract}
Resumo
O desconstrutivismo surge como uma estratégia originária do filósofo do século $\mathrm{XX}$, Jacques Derrida, a qual tem como base desierarquizar conceitos demasiadamente estruturados. 0 mesmo tem sua origem na literatura, mas seus conceitos foram traduzidos a diversas áreas, como cinema, arquitetura e design. Dessa forma, a presente pesquisa tem como questão norteadora de que forma a moda apropria-se do desconstrutivismo de Derrida para a criação de coleções. Objetiva compreender os conceitos e as características do desconstrutivismo e da moda desconstrutivista, por meio de uma breve análise do trabalho de estilistas como Martin Margiela, Yohji Yamamoto, Rei Kawakubo (à frente da marca Comme des Garçons), Issey Miyake e Jum Nakao. A natureza da pesquisa é básica, com o procedimento técnico classificado como pesquisa bibliográfica, a partir de autores como Derrida (1967), Vasconcelos (2003) e Loscialpo (2011). Percebe 0 desconstrutivismo como um movimento iniciado nos anos 1980, como crítica a própria compreensão da moda, onde antigos conceitos já consolidados podem, e devem, ser desmontados, repensados/reformulados.

$\begin{array}{lcr}\text { Palavras-chave: } & \text { Desconstrutivismo. } & \text { Moda } \\ \text { desconstrutivista. } & \text { Jacques } & \text { Derrida. }\end{array}$
\end{abstract}

Desenvolvimento de coleção.

\begin{abstract}
Deconstructivism emerges as an original strategy of the twentieth century, with Jacques Derrida, a hierarchical base of a hierarchy of concepts. Oneself, has its origin in the literature, but its concepts have been translated to diverse areas, like cinema, architecture and design. Thus, the present research has as a guiding question how fashion appropriates the deconstructivism of Derrida for the creation of collections, therefore. Aims to understand the concepts and characteristics of deconstructivism and deconstructivist fashion, through from a brief analysis of the work of designers such as Martin Margiela, Yohji Yamamoto, Rei Kawakubo (ahead of the Comme des Garçons brand), Issey Miyake and Jum Nakao. The nature of the research is basic, with the technical procedure classified as bibliographic research, based on authors such as Derrida (1967), Vasconcelos (2003) and Loscialpo (2011). Perceive the deconstructivism as a movement begun in the 1980s, as a criticism of the understanding of fashion itself, where old concepts already consolidated can and should be disassembled, repeated and/or reinterpreted.
\end{abstract}

Keywords: Deconstructivism. Deconstructive fashion. Jacques Derrida. Collection development.

Recebido em: 11/04/2019

Aceito em: 28/06/2019 


\section{INTRODUÇÃO}

O desconstrutivismo surge como uma estratégia originária do filósofo do século XX, Jacques Derrida, a qual tem como base desierarquizar o formato dos conceitos. 0 mesmo tem sua origem na literatura, mas seus conceitos foram traduzidos a diversas áreas, como cinema, arquitetura e design. No âmbito da moda, a prática desconstrutivista surgiu na década de 1980, influenciada pelo minimalismo na sua própria forma de arte e cultura, por meio do trabalho de estilistas como Martin Margiela, Yohji Yamamoto, Rei Kawakubo - à frente da marca Comme des Garçons -, Issey Miyake e, no Brasil, Jum Nakao com o icônico desfile "A Costura do Invisível" em 2004

Esta pesquisa visa investigar alguns conceitos do desconstrutivismo de Derrida, o qual tem sua origem na área da literatura e promove uma disseminação no campo da criação, bem como, compreender o funcionamento da moda desconstrutivista. Este trabalho também serve como ponto inicial para o aprofundamento do tema em estudos futuros. $\mathrm{O}$ assunto a ser discutido passou a chamar a atenção dos pesquisadores pela pouca produção bibliográfica no âmbito nacional onde este seria o início para uma discussão maior.

Portanto, a presente pesquisa tem como questão norteadora descortinar como a moda apropria-se do desconstrutivismo de Derrida para a criação de coleções. De forma a auxiliar na resolução desta questão, tem-se como objetivo geral identificar as características do desconstrutivismo de Derrida e da moda desconstrutivista para compreender como o mesmo deuse na área. Já os objetivos específicos consistem em contextualizar a estratégia do desconstrutivismo; conceituar a moda desconstrutivista e realizar uma breve análise acerca de coleções de moda dos estilistas supracitados, os quais se destacam referente à suas obras desconstrutivistas.

No que diz respeito à metodologia da pesquisa, o desenvolvimento teórico é de natureza básica, a qual, de acordo com Prodanov e Freitas (2013, p. 126), consiste em envolver "verdades e interesses universais, procurando gerar conhecimentos novos úteis para o avanço da ciência, sem aplicação prática prevista". Ainda de segundo os autores, a classificação enquanto procedimento técnico é a pesquisa bibliográfica, por utilizar materiais publicados previamente como fonte de conteúdo para o embasamento teórico. 
Após a parte introdutória, a fundamentação teórica aborda conceitos de Derrida (1967), Vasconcelos (2003) para a compreensão acerca do desconstrutivismo e suas características. Na seção seguinte, são definidos os conceitos de moda desconstrutivista a partir das leituras de Loscialpo (2011), Kiziltunali (2012), Fogg (2013) e a terceira seção apresenta uma breve análise de uma coleção de cada estilista supracitado considerando a ideia desconstrutivista.

\section{DESCONSTRUTIVISMO}

O desconstrutivismo surge e faz parte de uma das estratégias do filósofo francês do século XX, Jacques Derrida. Há procura por desconstruir a estrutura, ou seja, formatos sedimentados e promove a reflexão sobre a estrutura dos signos e a discussão dos sentidos das estruturas estudas (FOGG, 2013). Ele acontece em meio a corrente questionadora pós-guerra, concomitante ao surgimento do Surrealismo, o qual se rebela em relação à cultura conservadora, estabelecida durante a década de 1960 no país. Época essa em que, segundo Silva (2004, p. 1), acreditava-se "na existência de um conhecimento em estado puro, numa verdade consolidada, conferida à palavra (logocentrismo), que, por ser independente de qualquer contexto ou circunstância, pudesse ser adequadamente resgatada dos textos". Dessa forma, a desconstrução surge como um movimento para refletir e questionar este pensamento, valorizando a subjetividade e tudo aquilo que faz parte do intangível.

Assim, a desconstrução consiste não apenas no oposto do logocentrismo, mas em algo que ultrapassa o signo e busca a problematização do sentido, de forma a querer eliminar uma compreensão definitiva e estabelecida sobre os significados como intercambiáveis. De acordo com o pensamento desconstrutivista, um signo pode acabar se transformando em outro, que através de uma releitura pode se tornar outro e assim sucessivamente, um ciclo interminável (SILVA, 2004).

Associada ao pós-estruturalismo ${ }^{1}$, a desconstrução propõe a dissolução da hierarquia dos conceitos, onde o primeiro passo para um questionamento desconstrutivo é utilizar do segundo conceito, como se ele fosse o principal e procedente, sem considerar a criação de um terceiro conceito, conforme exemplifica o autor Vasconcelos (2003), onde na relação de causa e efeito, primeiro observa-se a manifestação dos efeitos para que, assim, possa-se reconstruir suas causas.

\footnotetext{
1 "Utiliza a teoria estruturalista para questionar e tornar problemáticas - mas não negar - as premissas do próprio estruturalismo" (VASCONCELOS, 2003, p. 74). Segundo o mesmo autor, o estruturalismo atinge camadas profundas, porém o pós-estruturalismo emerge ainda mais fundo.
} 
Deste modo, a dispersão da hierarquia dos conceitos, proposta pela desconstrução, constitui-se no jogo, termo utilizado por Derrida para se referir à oscilação entre a causa e efeito, bem como, a indecisão repetida causada por ele. O jogo, na literatura, questiona a palavra, os signos e os significados que ela se refere, surgindo como uma forma de compreender a relação entre conceitos (DERRIDA, 1967).

Portanto, a primeira fase do desconstrutivismo é o "derrubamento", tendo em vista a dissolução das hierarquias, para então, entender o jogo existente entre os dois conceitos, pois a falta de qualquer uma das fases tornaria a desconstrução incompleta. Meneses (2013, p. 185) conceitua a desconstrução como uma desestruturação - diferente de destruição - de forma a "desfazer algumas etapas estruturais do sistema, enquanto que indica, também, que vai no mesmo sentido: desfazer uma edificação para ver como está constituída ou desconstruída". Assim, a estratégia desconstrutivista possui regras e são os métodos que devem ser desconstruídos.

A desconstrução consiste num ato de leitura, a fim de originar em uma "reescritura" do texto, no qual não se tem como propósito a apropriação dos passos utilizados para a criação do primeiro, mas sim, criar uma certa releitura do mesmo. Através dessa releitura, surge uma "transformação do conceito de realidade, ocupando-se de uma realidade, mais real do que a própria realidade" (MENESES, 2013, p. 182). Derrida (1967) propõe a desconstrução de forma a cada nova leitura traduzir de diferentes modos, gerando novos conceitos e novos objetos. Desconstrução é leitura, tradução e releitura. É saber ler aquilo que está escondido, trazer à tona pontos não foram observados anteriormente de forma diferente, buscar a criação de um novo objeto com base naquilo já escrito por meio da sua compreensão, sempre diferente ainda de um próximo.

Dessa forma, com a intenção de decompor os discursos no qual se está trabalhando - ou desconstruindo - acaba-se por revelar suas hipóteses, ambiguidades e paradoxos. A desconstrução consiste, segundo Pedroso Junior (2010, p. 11):

[no] trabalho no interior dos discursos sustentadores do pensamento metafísico ocidental, já que esta seria, então, a melhor forma de abordá-los, desestabilizá-los e, por conseguinte, ampliar seus limites ou limiares. Diante disso, não nos causará estranhamento que a Desconstrução, ao interrogar incansavelmente os diferentes discursos que pretende decompor, operará, muitas vezes, no terreno da ambivalência, da duplicidade e da dubiedade, pois não incorrerá em reducionismo diante das oposições binárias com as quais a metafísica ocidental está acostumada a operar. 
Em vista disso, o pensamento desconstrutivo gerou grande impacto por apresentar esse caráter de questionar e achar novos significados aos conceitos já escritos. Contudo, a desconstrução não é sinônimo de destruição, mas sim uma estratégia dotada de métodos a fim de questionar, decompor e reorganizar conceitos (PEDROSO JUNIOR, 2010).

Silva (2004, p. 2) indica a desconstrução como "a transformação de um texto em outro texto", de forma que este nunca será igual ao primeiro, pois cada jogo possui significados instáveis:

E a cada escritura do texto, a malha de significados é tecida de acordo com o trabalho do leitor/tradutor, transformando o processo num jogo, que torna-se diferente e possui regras próprias a cada momento em que o jogador é substituído por outro. A leitura desconstrutora da escritura deixa à mostra a estrutura encoberta pelo texto (SILVA, 2004, p. 1).

Dessa forma, o leitor passa a receber outro cargo - o de autor - considerando que por meio da leitura ele acaba por fazer a sua própria reflexão e tradução daquilo que leu. Por conseguinte, a tradução - ou desconstrução - serve como uma certa abertura, de forma a descobrir novas diferenças e significados os quais não haviam sido percebidos anteriormente. "É somente através desta abertura que o original sobrevive, se transforma e se enobrece" (SILVA, 2004, p. 3).

O desconstrutivismo derridiano surge como uma crítica aos limites impostos aos conceitos, a fim de criar uma forma de pensamento que vá além desses limites. Assim, torna-se possível a criação de novos modos de construção por meio da criatividade unida ao poder de analisar o jogo existente entre os termos. Portanto, desvendando os diversos significados de um texto pode-se a partir daí decompor a sua estrutura, encontrando certa motivação para a criação de novos conceitos, juntamente com a dissociação do valor das oposições, surgindo efeitos entre o jogo de diferenças, não apenas significados. Considerando que, a intenção da desconstrução não é negar a existência dessas oposições, mas sim, achar o sentido delas, após tê-las desconstruído (MENESES, 2013).

Assim, Meneses (2013, p. 187-188), indica a segunda fase do desconstrutivismo, a "reconstrução", onde:

Esta será o aspecto originário do acto desconstrutivo: simples processo de dessedimentação, que se situa estruturalmente fora da Metafísica. Se a desconstrução fosse somente a inversão dos termos do binómio, falando materialmente, então seria substituir uma presença por outra. O movimento de "des-sedimentação" encarrega-se de deslocar a ordem hierárquica, fazendo com que se veja como transfundo, que se denomina "reinscrição", a incomunicabilidade de opostos. [...] Com efeito, a desconstrução consiste em produzir, discursivamente, o Outro, a partir de si mesmo. 
Portanto, procura-se entender como a moda se apropria do desconstrutivismo e suas características para a criação de coleções. Na próxima seção, apresentam-se conceitos sobre a moda desconstrutivista e a sua possível costura conceitual.

\subsection{Moda desconstrutivista}

O desconstrutivismo atravessou as estruturas da literatura, onde outras áreas passaram a utilizar de seus conceitos para repensar significados, como a arquitetura e o design. No âmbito da moda, a prática desconstrutivista surgiu na década de 1980, influenciada pelo minimalismo de estilistas como Martin Margiela, Yohji Yamamoto, Rei Kawakubo - à frente da marca Comme des Garçons - e Issey Miyake. A moda desconstrutivista consiste num movimento que buscou transformar a moda tradicional como era conhecida até então, apropriando-se das características da desconstrução proposta por Derrida a fim de questionar convenções do sistema da moda, principalmente acerca da relação corpo x roupa (LOSCIALPO, 2011). No Brasil, podemos notar esse movimento desconstrutivista na coleção desenvolvida pelo estilista Jum Nakao, "A Costura do Invisível" desfilada na São Paulo Fashion Week de 2004, por meio de um desfile performance.

Segundo Fogg (2013), na moda a desconstrução surge com o objetivo de deixar à mostra certas partes da peça que normalmente estão ao lado avesso, como pences, alinhavos, forros. Isto parte do conceito do jogo literário da desconstrução, bem como a inversão, deslocamento e dissolução de estruturas e conceitos. Utiliza-se técnicas advindas da reciclagem, com o uso de materiais inusitados e reaproveitamento de peças e objetos de diferentes segmentos e, com finalidades distintas daquelas na qual serão utilizadas, ao invés do uso de componentes habituais, "o mais importante elemento da moda desconstrutivista é chamar atenção para a construção de uma peça" (FOGG, 2013, p. 498).

Outros elementos, como a decomposição e a desintegração, são citados por Fogg (2013), como características para a desconstrução na moda. Dessa forma, a moda procura se apropriar do desconstrutivismo para mostrar o processo pelo qual a peça passou até chegar ao resultado final, como é visto nas passarelas, mostrando não apenas a peça pronta, mas sim o processo produtivo por trás da construção dela, "o ato de brincar com as convenções que regem a produção e o consumo da moda e de subvertê-las é outra expressão generalizada do desconstrutivismo" (FOGG, 
2013, p. 501). A moda possui convenções, costumes e conceitos binários, a desconstrução surge a fim de descosturá-los e confrontar certas relações.

A moda consiste em uma forma de expressão, onde nossas escolhas refletem aquilo que somos ou gostaríamos de ser (CARVALHAL, 2016), bem como, a moda está presente no museu, na indústria, em toda parte pelas ruas e na mídia. Dessa forma, a moda produz conteúdo e informação "24/7", ou seja, vinte e quatro horas por dia, durante os sete dias da semana, provocando efeitos ambíguos. O sistema da moda percorre a busca pelo novo e pela vontade de expressão da individualidade juntamente aos valores e significações culturais modernas, visto que

[...] cada criador prossegue sua trajetória própria, avançando seus próprios critérios. A moda aproximou-se ao mesmo tempo da lógica da arte moderna, de sua experimentação multidirecional, de sua ausência de regras estéticas comuns (LIPOVETSKY, 1989, p. 125).

Segundo Santos (2016) a principal função da moda é a de vestir, onde qualquer produto seja ele de vestuário, calçados ou acessórios - é criado com o intuito de utilização para vestir ou cobrir um corpo, um indivíduo, sendo por vaidade e/ou pudor. Com o tempo, a roupa também passou a ter a função de adornar, diferenciar classes ricas e pobres, tribos, culturas, tornando-se símbolo de singularidade e de diferenciação de grupos, gerando certas convenções.

Dessa forma, o setor da moda envolve diferentes processos criativos para o desenvolvimento de produto, produzindo suas peças com base no "ethos de estilo e a possuir uma preocupação com o design do produto, com as questões formais e estéticas, que, em contextos capitalistas, produzem a diferenciação nos bens e participam no estímulo ao consumo" (SANTOS, 2016, p, 107).

Portanto, a moda possui diversas convenções, visto que ela possui um alto poder de comunicação. Entre elas, pode-se citar duas principais: o desejo de preservar o pudor, de forma a cobrir partes do corpo que não devem ser mostradas (o que está diretamente ligado à relação corpo x roupa) e a moralidade, onde itens de luxo representam vaidade, considerado um pecado (mais próximo de questionamentos acerca de status e desigualdade social). Além dessas, existem diversas outras discussões atribuídas pela influência do vestuário como símbolo religioso, cultural e político. Isso serve para mostrar uma das facetas da moda, como forma de consumo de símbolos, por meio da identificação com a roupa e com determinado grupo (SVENDSEN, 2010). 
Em vista disso, Loscialpo (2011) cita um estado mais empírico do envolvimento do desconstrutivismo com a moda, a partir da influência da arte. A autora acredita que os estilistas não utilizam apenas da desconstrução da estrutura das peças, mas acabam por repensar na função e no significado da própria peça. Dessa forma, surge o questionamento sobre a relação entre o corpo e a roupa, o conceito do corpo em si e do próprio sujeito com a sua individualidade. A criação de roupas através da desconstrução questiona, inclusive, a compreensão da moda, na qual antigos conceitos já consolidados podem, e devem, ser desmontados, repetidos e reestruturados/recosturados.

Como movimento, a moda desconstrutivista chegou a ser descrita como pós-punk, grunge, ou até anti-moda durante a década de 1980. Porém, logo se percebeu que ela não consiste apenas na destruição de uma peça, mas sim em uma análise mais profunda e intelectual sobre as relações entre a roupa e o corpo, por meio do pensamento crítico e da condição moderna. Ao deparar-se com as condições determinantes da moda nos dias atuais, o trabalho dos estilistas a partir da desconstrução consiste numa reflexão crítica sobre as técnicas de adaptação tradicionais, bem como, dos padrões da consciência sobre o corpo humano. Assim, a moda desconstrutivista procura desafiar as oposições tradicionais entre sujeito e objeto, bem como, dentro e fora, de modo subjetivo, com as variáveis de tempo e espaço, não esquecendo suas necessidades, afirmações e negações (LOSCIALPO, 2011).

Segundo Kiziltunali (2012), a moda é desconstrução, na qual resulta em um processo sem fim, habitando o passado, o presente e o futuro, já que, ela se desconstrói de forma a se reconstruir e tornar-se moda novamente, dessa forma, a moda não é criação, mas sim a reinterpretação. A estratégia desconstrutivista surgiu na moda durante os anos 1980, como reflexo de uma época na qual a corrente pós-estruturalista proporcionou certo questionamento acerca das estruturas existentes e, admite como características o incompleto, destruído, inacabado, reciclado.

Dessa forma, a desconstrução envolve a alteração dos padrões convencionais que envolvem a moda, possuindo uma dimensão teórica importante. Ela consiste numa forma de revelar as operações, a estrutura e os discursos do sistema da moda, bem como, seu mecanismo, linguagem e aspectos comunicativos (KIZILTUNALI, 2012). 
Após a apresentação de conceitos acerca do desconstrutivismo de Derrida e sobre a moda desconstrutivista, a próxima seção tem por intenção mostrar a apropriação de alguns estilistas sobre a desconstrução em suas coleções.

\title{
3 A APROPRIAÇÃO DO DESCONSTRUTIVISMO EM COLEÇÕES DE MODA
}

O movimento da moda desconstrutivista acarretou numa imagem de moda conceitual e de vanguarda ${ }^{2}$. A presente seção pretende realizar uma breve correlação acerca de uma coleção de cada um dos estilistas: Martin Margiela, Yohji Yamamoto, Rei Kawakubo, Issey Miyake e Jum Nakao, a partir de características desconstrutivistas abordadas em seus trabalhos.

Seguindo os passos do The Antwerp Six ${ }^{3}$, Martin Margiela, estilista belga famoso por suas peças de caráter inacabado e com "defeitos", o qual expunha em suas peças as costuras e forros, bem como, de modificar o lugar de costurar as mangas, ombros e cintura. Com isso houve "uma desconstrução para um novo construir; um tipo de paradoxo que acabou se firmando na moda" (BRAGA apud MARIANO, 2011, p. 115).

Dessa forma, a cada coleção Margiela questiona os critérios impostos pelo sistema mercadológico da moda, a qual revela sua expressividade ao confrontar seu sistema. $O$ estilista faz referências a questões relacionadas a peças com aspecto inacabado e desconstruído/em processo, bem como, a utilização de materiais e formas incomuns para a criação de suas peças, além de trazer críticas sobre a relação do corpo com a roupa e, também do sujeito $\mathrm{x}$ objeto (MARIANO, 2011). Portanto, a autora também indica a importância do exercício de desconstruir as peças para entender a sua estrutura, de forma que:

\begin{abstract}
O exercício de desconstruir um artefato para compreendê-lo estabelece um diálogo entre o observador e o designer. Ao dissecar um traje e verificar sua estrutura, podemos compreender o raciocínio do designer, seu modus facendi. É como se ele nos relatasse uma história interessante e repleta de segredos, numa linguagem muito específica escrita nas entrelinhas dos tecidos, costuras, cortes, aviamentos e adornos (MARIANO, 2011, p. 131).
\end{abstract}

\footnotetext{
${ }^{2}$ No âmbito da moda, em relação ao vestuário, a palavra vanguarda refere-se a certas modificações nos significados de peças de roupas, não coincidindo com as finalidades "normais" propostas por ela, bem como, na utilização de materiais e objetos os quais não possuem são específicos para aquela proposta, porém são redefinidos a ponto de passar a ser, naquele contexto (CRANE, 2006).

3 O Grupo dos Seis (tradução nossa), composto por seis estilistas belgas, entre eles Dries Van Noten, Ann Demeulemeester, Walter Van Beirendonck, Dirk Van Saene, Marina Yee e Dirk Bikkembergs, os quais se mudaram para Londres em 1986 com o intuito de expor suas coleções. Eles caíram no gosto do editor da i-D pela estética radical e vanguardista de suas coleções, apresentando aspectos minimalistas, a qual emergiu a moda dos anos 1990. Disponível em: http://cultpopshow.com.br/the-antwerp-six-e-a-moda-belga/. Acesso em: 02 jun. 2016.
} 
Portanto, como exemplo do trabalho de Margiela, a Figura 1 retrata a coleção de Primavera 2009, desfilada na Paris Fashion Week (PFW).

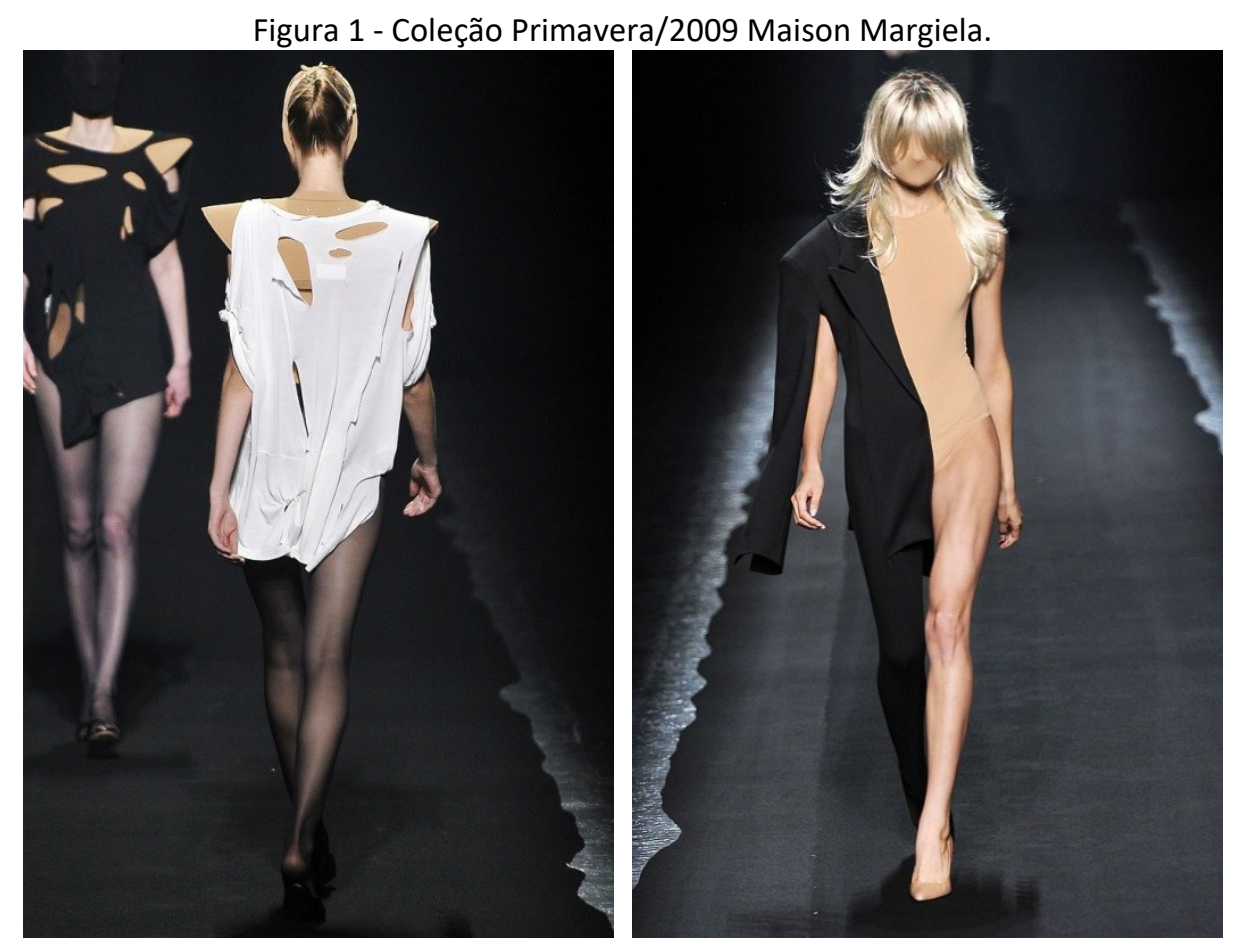

Fonte: Mower (2008).

A coleção desenvolvida por Margiela para primavera/2009 apresenta uma forte característica desconstrutivista, na qual as modelos desfilam com os rostos cobertos, representando a dissolução da hierarquia conceitual entre corpo e vestuário, descaracterizando-as como o costume do padrão de beleza da indústria/mercado. Essa coleção comemorou os 20 anos de Martin Margiela à frente da marca, realizando uma revisão de coleções passadas do estilista, porém inovando na utilização dos materiais, por meio das formas geométricas de suas roupas, o uso de perucas tanto de maneira usual na cabeça (MOWER, 2008).

Na Figura 1 pode-se observar uma das modelos vestindo uma peça com furos e aspectos destruídos, a qual possui uma silhueta solta, sem acentuar as curvas do corpo, bem como, uma espécie de ombreira, alongando a linha dos ombros e jogando com a forma do mesmo. Margiela também seguiu nesta coleção o culto ao inacabado, onde a modelo da direita veste apenas a metade de uma espécie de macacão e, a parte de cima refere-se a um blazer, que possui a manga 
aberta, por onde passa seu braço, além de usar perucas, macacões e bodies da cor da pele referindo-se ao corpo nu. Segundo Lee (2012), o estilista contesta suas próprias criações, utilizando da criatividade e formas achatadas no uso da alfaiataria, desconstruindo essa forma tão tradicional de fazer moda. Suas formas estruturais transcendem o funcional, de maneira a realizar críticas desconstruindo o corpo industrializado, por meio da criação na moda.

No que diz respeito ao trabalho de Yohji Yamamoto, foi escolhida a coleção desfilada na Paris Fashion Week (PFW) de outono/2017, conforme ilustra a Figura 2.

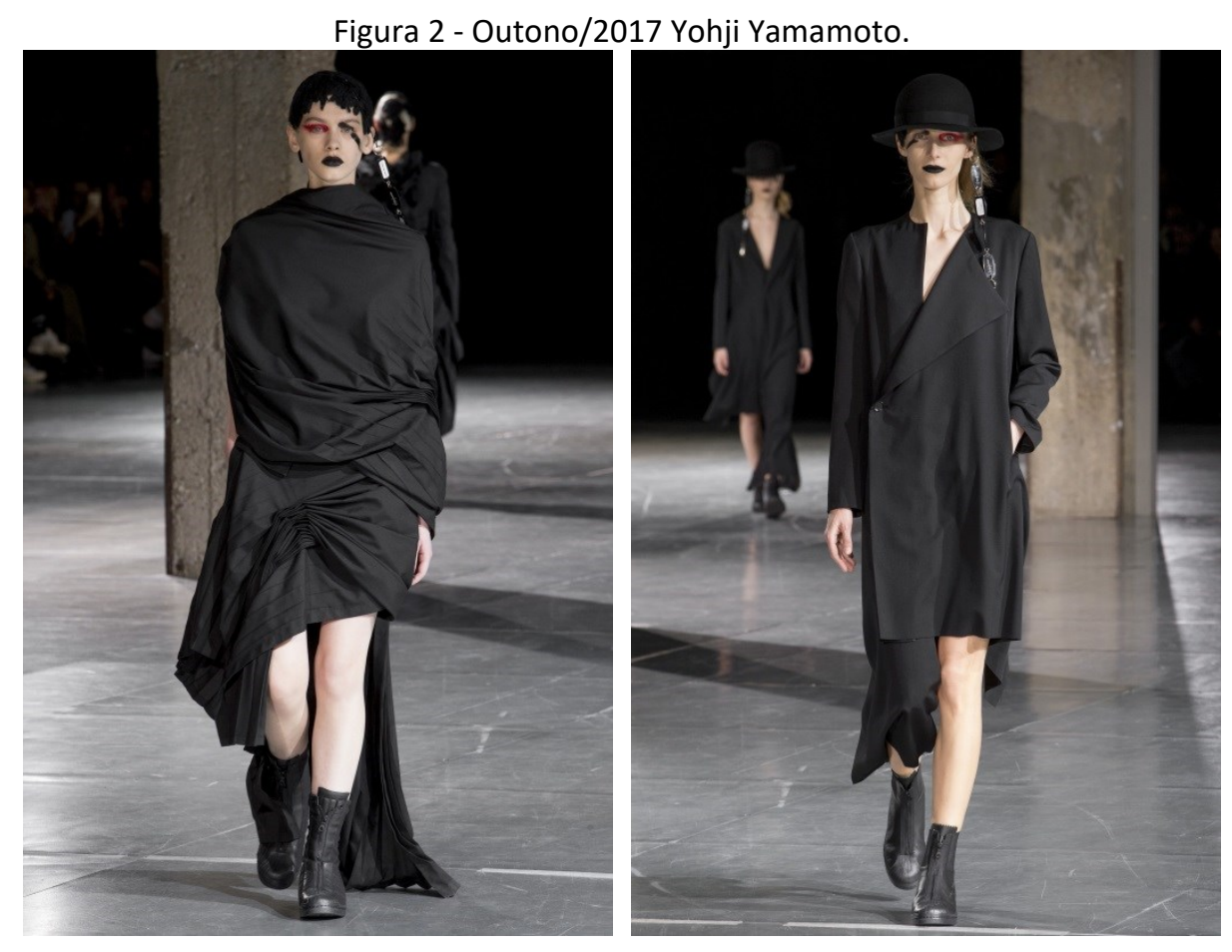

Fonte: Verner (2017).

O trabalho de Yohji Yamamoto para a coleção outono/2017 transcendeu com pregas horizontais que descaracterizam a roupa mercantil, bem como, admite uma expansão volumétrica de forma dimensional e desconstrói formas habituais de modo que, as duas práticas eram inseparáveis. Através da desconstrução, Yamamoto transformou camisas, vestidos e casacos, apropriando-se da desconstrução na moda (VERNER, 2017).

A Figura 2 apresenta looks completamente pretos, com assimetrias e pouco volume - na comparação com as outras coleções aqui apresentadas - retrata aldeia da desconstrução em uma 
linha mais sutil. À esquerda, uma espécie de vestido que envolve a modelo por inteiro, como um "saco", com uma abertura para a cabeça e para as pernas, cobrindo seus braços, trazendo uma linha reta ao corpo feminino e formas através das pregas na horizontal, com assimetria e uma cauda. O look apresentado à direita consiste em um blazer com sua forma reconstruída, mantendo a linha reta, bem como a anterior, ignorando as curvas do corpo e a assimetria aparece na abertura frontal, com meia gola e na parte de trás, transformando-se em um vestido envelope.

Já quanto ao trabalho de Rei Kawakubo, estilista da marca Comme des Garçons, escolheuse o desfile realizado para a Paris Fashion Week (PFW) de primavera 2016, apresentado na Figura 3.

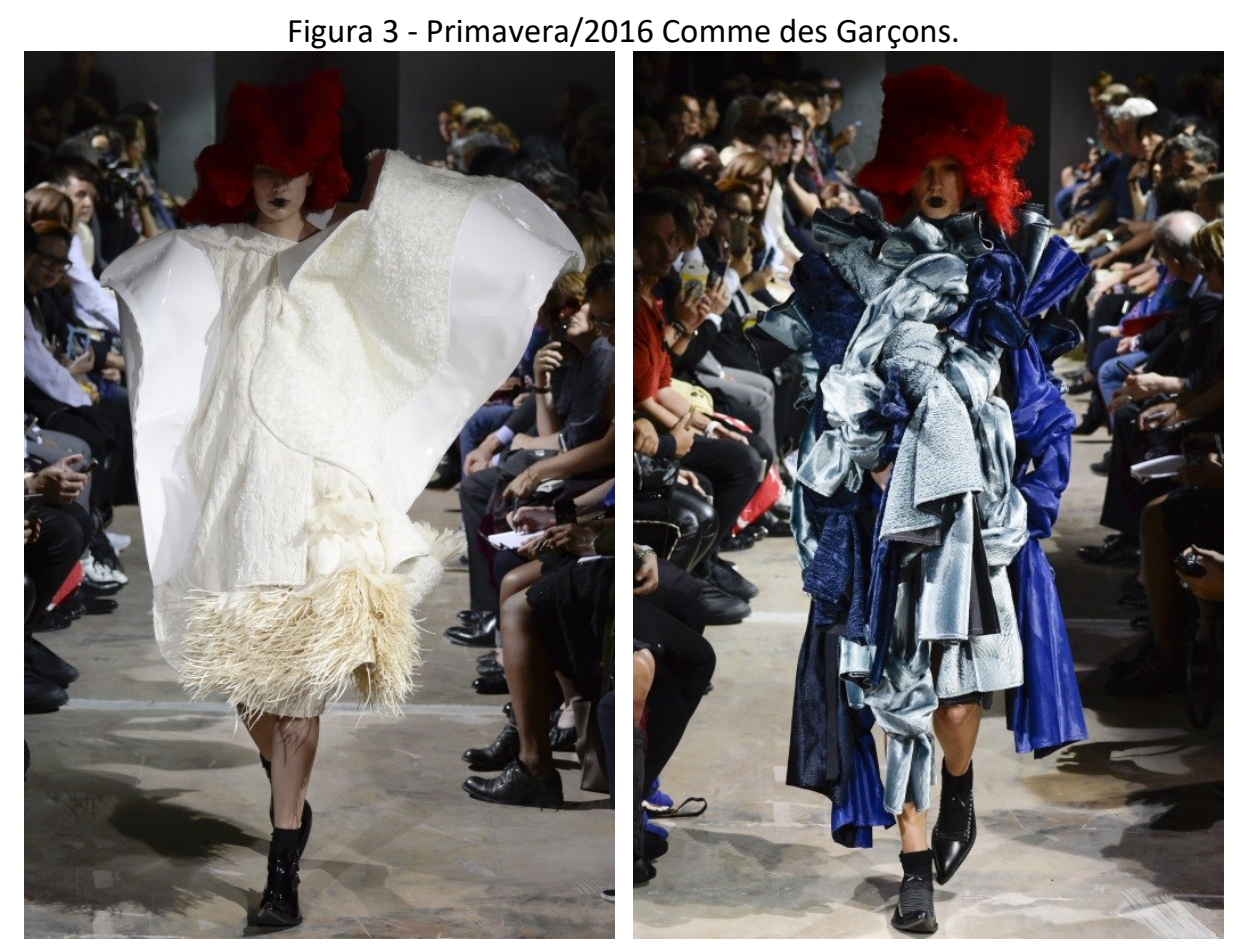

Fonte: Mower (2015).

A coleção desenvolvida traz novamente a principal característica da marca: a transferência da roupa. Com a sua prática desconstrutivista, ela continua a mostrar que por meio da moda é possível tanger significados mais profundos durante um período de mudança industrial - de forma perturbadora aos olhares, busca questionar o sentido e ultrapassa o setor imperativo do mercado, apresentando seu trabalho de uma forma experimental e única (MOWER, 2015). 
A partir de seu trabalho, Rei Kawakubo corrobora com a sua preocupação acerca das formas e a modelagem de suas roupas, realizando distorções do corpo e, criando novas formas, ao invés de seguir com as formas do corpo feminino, conforme é realizado pela moda comercial (LEE, 2012). Conforme ilustrado na Figura 3, ambos os looks apresentam uma modelagem ampla, à esquerda, sem uma forma bem definida, com recortes, mistura de materiais e volume. O look da direita apresenta diversas mangas costuradas no entorno da peça, com nós volumosos, trazendo assimetria e a mistura de tons de azul, de forma inusitada afirmando as características da reconstrução de Kawakubo.

Após, a coleção outono/2011, do estilista Issey Miyake, desfilada na Paris Fashion Week (PFW), como mostra a Figura 4.

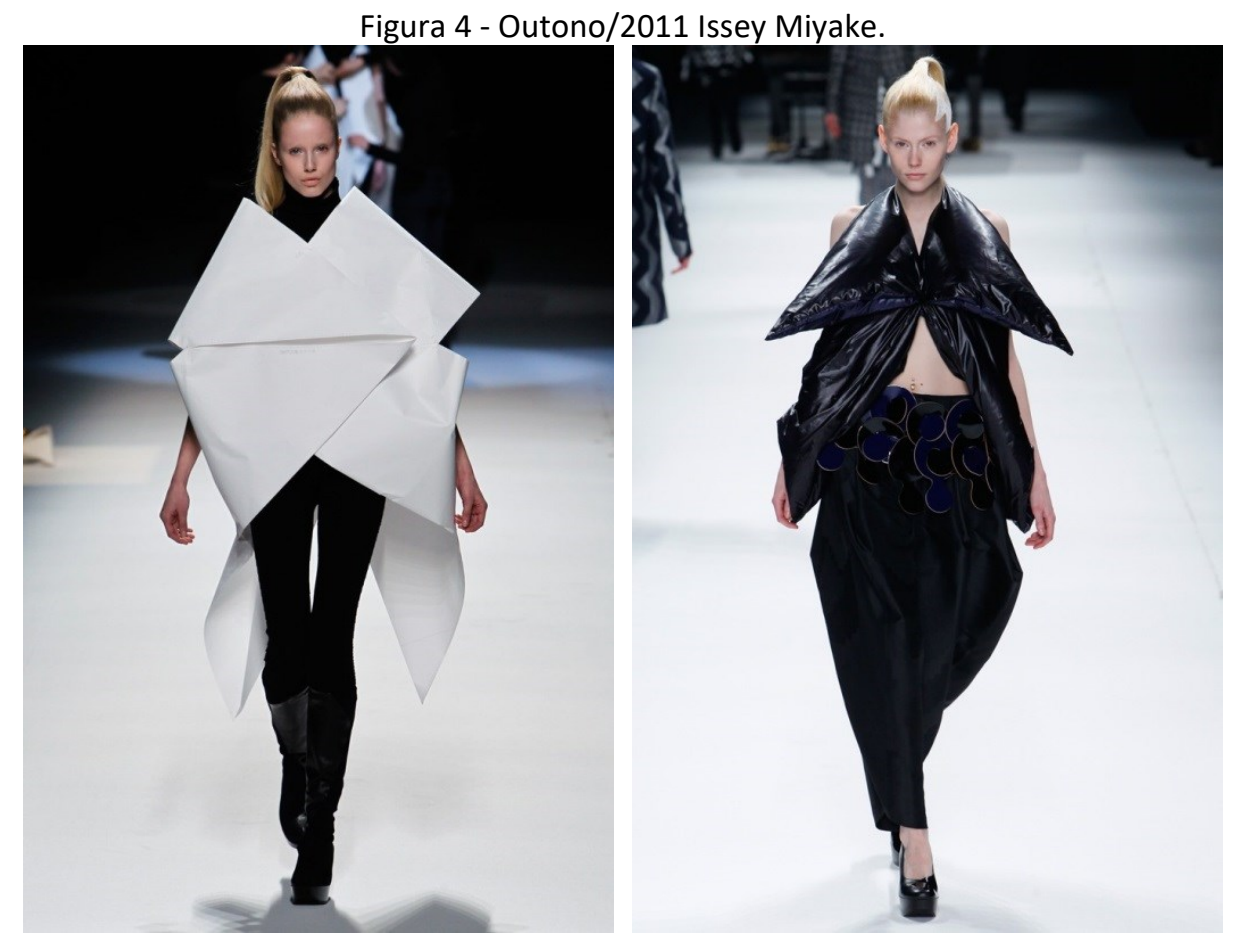

Fonte: Blanks (2011).

A coleção de outono/2011 de Miyake iniciou seu desfile com modelos vestindo roupas feitas de papel ${ }^{4}$, seguidas pela apresentação dos mesmas amostras de roupa, porém desenvolvidas em tecido, traduzindo o processo de design. Uma das principais características do estilista consiste

\footnotetext{
${ }^{4}$ As roupas feitas de papel, ou seja, o "origami" (dobradura de papel) é uma prática cultural herdada e aplicada pelo Miyake.
} 
na criação de ilusão de ótica, por meio de estampas e cores que parecem mudar de cor conforme a modelo desfila pela passarela, apresentando características desconstrutivistas com a apropriação da tecnologia do tecido (BLANKS, 2011).

Segundo Lee (2012), o estilista aproveita-se da tecnologia para fugir da arte tradicional em suas criações e experimentações, desenvolvendo peças de roupas onde a funcionalidade se expande através das metamorfoses de suas peças, que mudam de cor, formato e até transformamse em outras peças na passarela. Na Figura 4, à esquerda vê-se uma das peças desenvolvidas em papel, uma espécie de casaco geométrico, bastante amplo e com uma cauda atrás, por cima de um macacão todo preto e, à direita, a modelo veste uma blusa com uma gola pontuda, a qual parece ser inflável e uma calça larga. Ambos os looks possuem modelagem ampla e expandindo as formas do corpo feminino.

E, por fim, a Figura 5 retrata a coleção "A Costura do Invisível", desfilada em 2004 na São Paulo Fashion Week (SPFW), por Jum Nakao.

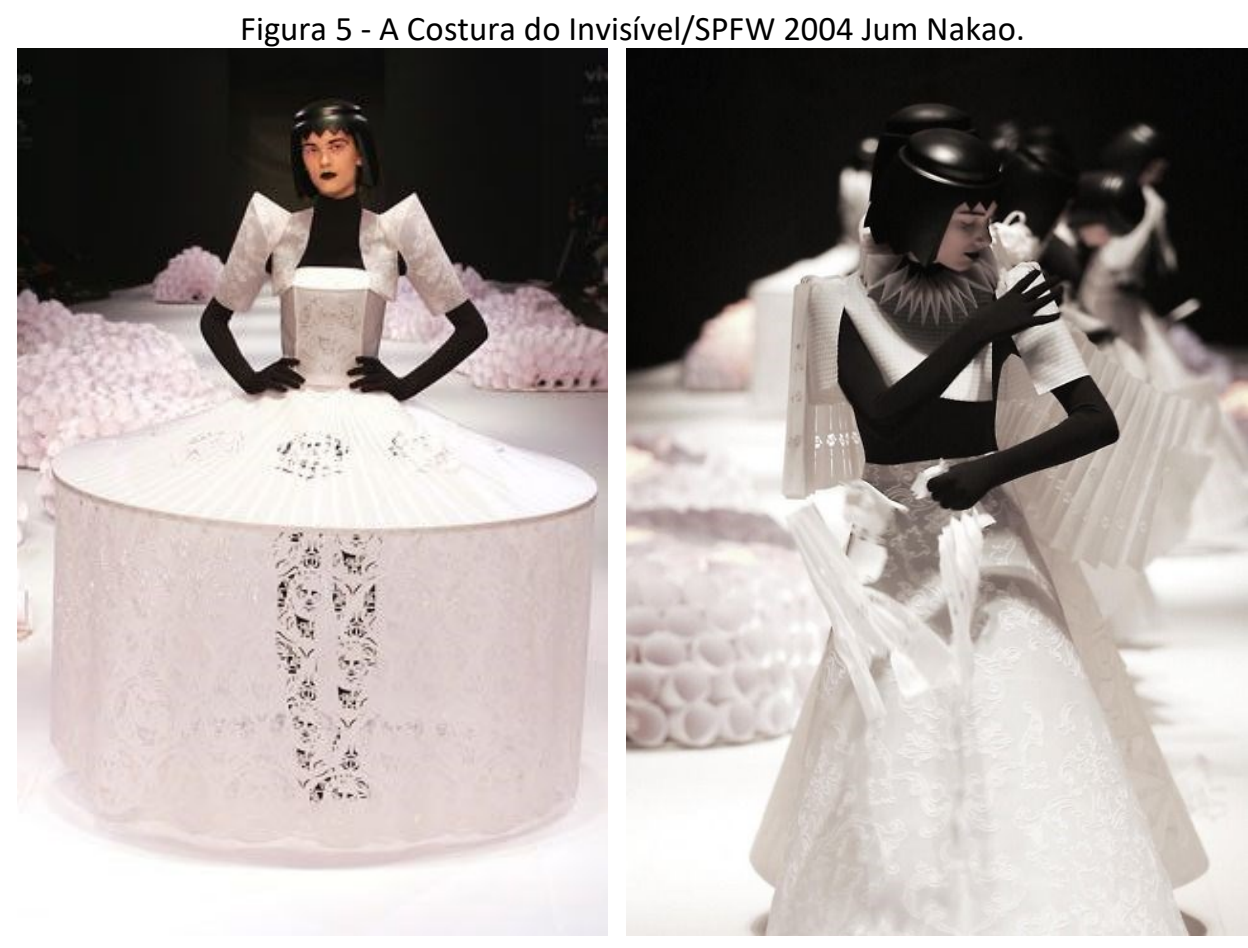

Fonte: Nakao (2004). 
O desfile de Nakao para o SPFW de 2004, com suas peças desenvolvidas em papel, teve inspiração na aristocracia do século XVII, a partir de vestidos delicados, com a cintura marcada, ombreiras exageradas e uma mistura entre saias curtas e longas. Através de uma representação de produtos de luxo, a ostentação e supervalorização de grandes marcas da época, as peças desenvolvidas em papel que, na performance da passarela, foram destruídas e rasgadas enquanto as modelos desfilavam, fez uma crítica aos produtos efêmeros oriundos da moda contemporânea, com um clima dramático (LEE, 2012).

Com o auxílio de máquinas tecnológicas, "as formas aparecem geometrizadas, nãohumanas, perfeitas (padronizadas, homogeneizadas) como na sociedade industrial dos brinquedos, um não-lugar em que tudo é perfeito, limpo" (LEE, 2012, p. 42). Na Figura 5, é possível ver à esquerda um vestido clássico, que lembra o período Vitoriano, com a cintura marcada, ombros exagerados e uma saia longa e ampla, já na direita, temos a cena da modelo destruindo o look na passarela, onde viu-se a destruição dos modelos criados como uma crítica à obsolescência dos produtos de moda.

Com isso, apresentou-se a análise de algumas coleções de estilistas conhecidos por suas criações desconstrutivistas, às quais busca por conceitos que possam ser aplicados no desenvolvimento de uma coleção de moda. Percebe-se, a dissolução da hierarquia dos conceitos utilizando o corpo e a roupa. A fim de obter a dissociação desses termos, precisa-se analisar e compreender o jogo que os une, de forma que, a roupa sempre é moldada e projetada conforme o tipo de corpo desejado. Desse modo, entende-se que o corpo é um suporte de criação, não à obediência mercadológica como causa e a roupa como efeito, onde a vestimenta é desenvolvida para proteger, adornar e comunicar o corpo do indivíduo. Na desconstrução deste conceito, utilizase de um corpo para vestir uma roupa, com formas, conceitos e acabamentos que não consideram a sua ergonomia. Com essa análise do jogo existente entre os dois conceitos propostos, surge a oportunidade da criação de novas formas de significação a favor do sentido, como visto nas coleções de Martin Margiela, Yohji Yamamoto, Comme des Garçons, Issey Miyake e Jum Nakao

Outra forma como é vista a desconstrução na moda é por meio de um aspecto inacabado, desgastado, reconfigurado utilizado, principalmente pelo estilista Martin Margiela. À vista disso, as peças de roupas são compostas de costuras internas para o seu fechamento, bem como alguns acabamentos propostos pela modelagem, como pences, forros, viés, entre outros, os quais são 
costurados do lado avesso da peça e precisam ser "invisíveis" ao lado direito. Ao compreender a construção de uma peça, passa-se a repensar na função e no significado desta e de seus acabamentos, resultando em um conceito desconstrutivista.

Esta reflexão conceitual pode resultar em diversas formas: ao utilizar matérias-primas recicladas, gerando questionamentos acerca do sistema mercadológico da moda; repensando na modelagem dessas peças, por meio da desconstrução da sua forma e reconstituindo outro corpo; aparência de inacabado, com a proposta de deixar à mostra tudo àquilo de deveria ser oculto aos olhos do mercado. Essas questões geram uma reflexão do que é convencionado, o que deve estar fora ou dentro, quem é o sujeito e o que é o objeto.

Portanto, a presente seção trouxe algumas possibilidades acerca da utilização do desconstrutivismo em coleções de moda, com exemplos de estilistas conhecidos pelas características aplicadas e, também, uma breve análise sobre a apropriação desse conceito na criação em moda. A seguir, apresentam-se as considerações finais deste estudo.

\section{CONSIDERAÇÕES FINAIS}

A estratégia desconstrutivista passou a ser aplicada no Design de Moda em meados dos anos 1980 por meio da alteração dos padrões convencionais apresentados nos desfiles de moda, de modo a buscar na criatividade novas formas de reconstrução, com a quebra dos paradigmas que causam estranhamento e provocam questionamentos sobre o sistema instaurado da moda.

Dessa forma, nas seções anteriores cumpriram-se os objetivos estabelecidos pela pesquisa, por meio da fundamentação teórica com as definições dos conceitos sobre o desconstrutivismo de Derrida e suas características, bem como sobre a moda desconstrutivista, a fim de compreender como a moda se apropria da desconstrução para a criação de coleções. Após a fundamentação foi apresentada uma breve análise acerca de coleções dos estilistas Martin Margiela, Yohji Yamamoto, Rei Kawakubo, Issey Miyake e Jum Nakao, em busca de conceitos que possam ser aplicados no desenvolvimento de uma coleção de moda, utilizando da desconstrução como processo criativo e moda transformadora.

Percebeu-se que o desconstrutivismo foi apropriado como forma de construção com um movimento iniciado nos anos 1980, como crítica da própria compreensão e produção da moda, na qual antigos conceitos já consolidados podem, e devem, ser remontados/recosturados. 
Em vista disso, a desconstrução faz parte de um processo criativo que envolve a criação de coleções, visto que o ato de criar admite a competência de compreender, além da aptidão em relacionar, caracterizar, compor e significar. A criação está diretamente ligada à formação, ou seja, formar refere-se a transformar, de forma que, o processo criativo se dá por meio da combinação de ideias e conceitos primários.

Na terceira seção, obteve-se o resultado entre o conceito da desconstrução-reconstrução por meio de uma breve análise acerca da apropriação de características do desconstrutivismo na moda, a partir do trabalho dos estilistas supracitados. Dessa forma, pode-se constatar a dissolução da hierarquia conceitual entre corpo e vestuário, conforme a descaracterização habitual das modelos, a discussão acerca da relação corpo x vestuário e a criação das roupas, por meio de modelagens amplas, não respeitando as formas do corpo feminino, para desmistificar a produção industrial e contrapor a vestibilidade das mesmas. Pode-se constatar a moda desconstrutivista como criação e geradora de sentidos.

Dessa forma, conseguiu-se refletir sobre o jogo existente entre dois conceitos que envolvem a moda, o corpo (causa) e a roupa (efeito), fazendo a transgressão das hierarquias. Também foi feita a leitura sobre a construção de uma peça a fim de entender o seu processo e repensar a função e o significado desta e de seus acabamentos, propondo alguns conceitos que possam ser aplicados para a reconstrução. Desconstrução trata-se de uma prática e conceito pósestruturalista e a moda consiste em um veículo de comunicação.

Este trabalho é um ponto inicial para o aprofundamento do tema em estudos futuros. $\mathrm{O}$ foco foi em apenas uma pequena parcela acerca da abrangência do desconstrutivismo e a sua possívet aplicação na moda, considerando o curto espaço para sua discussão.

\section{REFERÊNCIAS}

BLANKS, Tim. Fall 2011 ready-to-wear: Issey Miyake. Vogue, Paris, 03 Mar. 2011. Disponível em: https://www.vogue.com/fashion-shows/fall-2011-ready-to-wear/issey-miyake. Acesso em: 31 out. 2019.

CARVALHAL, André. A moda imita a vida: como construir uma marca de moda. São Paulo: Estação das Letras e Cores; Rio de Janeiro: Ed. Senac Rio, 2016.

CRANE, Diana. A moda e seu papel social: classe, gênero e identidade das roupas. Senac SP, 2006. 
DERRIDA, Jacques. De La Gramatologie. Paris: Les Éditions de Minuit, 1967.

FOGG, Marnie. Tudo sobre moda. Rio de Janeiro: Sextante, 2013.

KIZILTUNALI, Gizem. A deconstructive system: fashion. In: GLOBAL CONFERENCE INTERDISCIPLINARY.NET, 4., 2012, [s.I.]. Disponível em: https://www.inter-disciplinary.net/conferences/. Acesso em: 14 nov. 2019.

LEE, Erika Yamamoto. Jum Nakao: moda e pensamento artístico. 2012. Dissertação (Mestrado em Artes Visuais) - Centro de Artes, Universidade do Estado de Santa Catarina, Florianópolis, 2012.

LIPOVETSKY, Gilles. O império do efêmero: a moda e seu destino nas sociedades modernas. São Paulo: Companhia das Letras, 1989.

LOSCIALPO, Flavia. Fashion and philosophical deconstruction: a fashion in-deconstruction. Oxford: Inter-Disciplinary Press, 2011.

MARIANO, Maria Luiza Veloso. Da construção à desconstrução: a modelagem como recurso criativo no design de moda. 2011. Dissertação (Mestrado em Design) - Universidade Anhembi Morumbi, São Paulo. 2011.

MENESES, Ramiro Délio Borges de. A desconstrução em Jacques Derrida: o que é e o que não é pela estratégia. Universitas PhilosoPhica, Bogotá, v. 30, n. 60, p. 177-204, enero/jun. 2013. Disponível em: http://www.scielo.org.co/pdf/unph/v30n60/v30n60a09.pdf. Acesso em: 30 out. 2019.

MOWER, Sarah. Spring 2009 ready-to-wear: Maison Margiela. Vogue, Paris, 28 Sep. 2008. Disponível em: https://www.vogue.com/fashion-shows/spring-2009-ready-to-wear/maison-martinmargiela. Acesso em: 31 out. 2019.

MOWER, Sarah. Spring 2016 ready-to-wear: Comme des Garçons. Vogue, Paris, 03 Oct. 2015. Disponível em: https://www.vogue.com/fashion-shows/spring-2016-ready-to-wear/comme-desgarcons. Acesso em: 31 out. 2019.

NAKAO, Jum. A costura do invisível (Brasil). 2004. Disponível em: http://www.jumnakao.com/portfolios/a-costura-do-invisivel/. Acesso em: 30 out. 2019.

PEDROSO JUNIOR, Neurivaldo Campos. Jacques Derrida e a desconstrução: uma introdução. Revista Encontros de Vista, n. 5, p. 9-2, jan./jun. 2010. Disponível em: http://encontrosdevista.com.br/Artigos/Neurivaldo_Junior_Derrida_e_a_desconstrucao_uma_intr oducao_final.pdf. Acesso em: 30 out. 2019.

PRODANOV, Cleber Cristiano; FREITAS, Ernani Cesar de Freitas. Metodologia do trabalho científico: métodos e técnicas da pesquisa e do trabalho acadêmico. 2. ed. Novo Hamburgo: Feevale, 2013. 
SANTOS, Heloisa Helena de Oliveira. A definição da moda em contextos de economia criativa: o da UNCTAD/ONU e suas repercussões no Brasil. IARA: Revista de Moda, Cultura e Arte, São Paulo, v. 9 n. 1, p. 93-113, set. 2016. Disponível em: http://www1.sp.senac.br/hotsites/blogs/revistaiara/wpcontent/uploads/2016/09/123-lara-artigo.pdf. Acesso em: 30 out. 2019.

SILVA, Wanessa Gonçalves. Desconstrutivismo e o conceito de différance. ENCONTRO CELSUL:

Círculo de Estudos Lingüísticos do Sul, 6., 2004, Florianópolis. Anais [...]. Florianópolis, UFSC, 2004.

SVENDSEN, Lars. Moda: uma filosofia. Rio de Janeiro: Zahar, 2010.

VASCONCELOS, José Antonio. O que é a desconstrução?. Revista de Filosofia Aurora, Curitiba, v. 15, n. 17, p. 73-78 Curitiba, jul./dez. 2003. Disponível em:

https://periodicos.pucpr.br/index.php/aurora/article/view/3421/3337. Acesso em: 31 out. 2019.

VERNER, Amy. Fall 2017 ready-to-wear: Yohji Yamamoto. Vogue, Paris, 03 Mar. 2017. Disponível em: https://www.vogue.com/fashion-shows/fall-2017-ready-to-wear/yohji-yamamoto. Acesso em: 31 out. 2019. 